\title{
Kolonoskopiye bağlı iatrojenik kolon perforasyonu olgularımızın değerlendirilmesi
}

\author{
Evaluation of patients with iatrogenic colon perforation caused during colonoscopy
}

Tülay DIKEN ALLAHVERDI, Yusuf GÜNERHAN

Kafkas Üniversitesi Tip Fakültesi, Genel Cerrahi Anabilim Dal, Kars

Giriş ve Amaç: Kolonoskopik perforasyonlar nadir görülen komplikasyonlardır. Biz bu çalışmamızda kolonoskopi ile iatrojenik kolon perforasyonu tanısı konulan hastaların değerlendirilmesi amaçladık. Gereç ve Yöntem: Çalışmada Kafkas Üniversitesi Tıp Fakültesi Genel Cerrahi Endoskopi Ünitesinde Ocak 2008-Aralık 2017 tarihleri arasinda kolonoskopi yapılan hastalar arasından iatrojenik kolon perforasyonu tanısı konulanlar retrospektif olarak değerlendirildi. Kolonoskopi sirasında ve sonrasında iatrojenik kolon perforasyonu belirlenen olguların demografik özelliklerinin yanı sira klinik bulgular ve yapılan cerrahi girissimler takipleriyle birlikte kaydedildi. Bulgular: Endoskopi ünitemizde 1712'si erkek, 1850'si kadın olmak üzere toplam 3562 hastaya kolonoskopi yapıldığı belirlendi. Bunun 2561 tanesi total kolonoskopi, 1001 tanesi rektosigmoidoskopi idi. Bu olgularm 300 tanesine polip eksizyonu, 858 tanesine kolon biyopsisi yapıldı. Toplam 8 hastada iatrojenik kolon perforasyonu meydana geldi. Hastaların 7 tanesine işlem esnasinda, 1 tanesine ise 24 saat sonra kolon perforasyonu tanisi konuldu. Kolonoskopi sirasinda kolon perforasyonu tespit edilen hastalardan 5 tanesine primer kolorafi, 1 tanesine primer kolografi ve ince barsak rezeksiyon anastomozu ve geriye kalan birine ise Hartmann prosedürü uygulandı. Konoskopi işleminden 24 saat sonra kolon perforasyonu saptanan diğer hastaya da Hartmann prosedürü uygulandı. Sonuç: Kolonoskopi esnasında çeşitli predispozan nedenlerle perforasyon görülebilir. Perforasyonu olan hastalara erken dönemde primer onarım tercih edilirken, geç dönemde stoma açılmalıdır. Deneyimli merkezlerde konservatif tedavi de yapılabilir.

Anahtar kelimeler: Kolonoskopi, perforasyon, iatrojenik

\section{GİRIS}

Nadir bir komplikasyon olarak görülen kolonoskopik perforasyonlar merkezden merkeze göre sayı olarak değişmektedir. Kolon perforasyonunun tanisal kolonoskopilerde \%0.03$\% 0.65$, terapötik kolonoskopilerde ise \%0.073-2.14 oranında geliştiği bildirilmiştir (1). Perforasyonların \%53'ünün sigmoid ve rektosigmoid bileşkede, \%5'inin inen kolonda, \%15'inin transvers kolonda, \%15'inin çıan kolonda ve \%24'ünün çekumda görüldügü rapor edilmiştir (2). Kolon perforasyonunda tedavi yaklaşımı konservatif ve cerrahi yaklaşım olarak ikiye ayrılmaktadır. Küçük perforasyonlar, peritonit bulgusu olmayan hastalar, barsak temizliği iyi yapılan hastalar ve kolonoskopi sirasinda fark edilmeyen perforasyonlar konservatif olarak izlenebilir $(1,2)$. Cerrahi yaklaşımda ise açık
Background and Aims: Perforations developing during colonoscopy are rare. The aim of this study was to evaluate patients diagnosed with iatrogenic colon perforation caused during colonoscopy. Materials and Methods: We retrospectively evaluated patients who had been diagnosed with iatrogenic colon perforation caused during colonoscopy at the Kafkas University Faculty of Medicine's General Surgery Endoscopy Unit between January 2008 and December 2017. Demographic features, clinical findings, surgical intervention details, and follow-up data of the patients diagnosed with iatrogenic colon perforation during or after colonoscopy were recorded. Results: A total of 3,562 patients consisting of 1,712 males and 1,850 females had undergone colonoscopy at our colonoscopy unit. These procedures consisted of 2,561 total colonoscopies and 1,001 rectosigmoidoscopies. Polyp excision was performed in 300 and colon biopsy in 858 patients. Iatrogenic colon perforation developed in 8 patients in total, and the diagnosis was made during the procedure in 8 patients and $24 \mathrm{~h}$ later in 1 patient. Among those patients diagnosed during colonoscopy, primary colorrhaphy was performed in 5 patients, primary colography with intestinal resection anastomosis was performed in 1 patient, and the Hartmann procedure was performed in the remaining patients. The Hartmann procedure was also performed in the patient diagnosed with colon perforation $24 \mathrm{~h}$ after colonoscopy. Conclusion: Perforation can develop due to various predisposing conditions during colonoscopy. Primary repair is indicated in the early period and a stoma in the late period in these cases. Conservative treatment can also be used in experienced centers.

Key words: Colonoscopy, perforation, iatrogenic

cerrahi, endoskopik klip uygulamaları pratikte yaygın olarak yapılmaktadır $(1,2)$.

Biz bu çalışmamızda kolonoskopi ile iatrojenik kolon perforasyonu tanısı konulan hastaların değerlendirilmesini amaçladik.

\section{GEREÇ ve YÖNTEM}

Çalışmada Kafkas Üniversitesi Tıp Fakültesi Genel Cerrahi Endoskopi ünitesinde Ocak 2008-Aralık 2017 tarihleri arasında kolonoskopi yapılan hastalar arasından iatrojenik kolon perforasyonu tanısı konulanlar retrospektif olarak degerlendirildi. Kolonoskopi sirasında ve sonrasında iatrojenik 
kolon perforasyonu belirlenen olguların demografik özelliklerinin yanı sıra klinik bulgular ve yapılan cerrahi girişimler takipleriyle birlikte kaydedildi.

\section{BULGULAR}

Bu çalışma kapsamında 9 yllık süreçte 1712 tanesi erkek, 1850 tanesi kadın olan toplam 3562 hastaya kolonoskopi yapıldı. Erkeklerin yaş ortalaması 49 (minimum: 20, maksimum: 90), kadınların yaş ortalaması ise 39'du (minimum: 20, maksimum: 86). Ünitemizde bu süre boyunca hastaların 2561 tanesine total kolonoskopi, 1001 tanesine rektosigmoidoskopi yapılmıştı. Bu olgularımızın 300 tanesine polip eksizyonu, 858 tanesine de kolon biyopsisi yapıldı. 6'sı kadın 2'si erkek toplam 8 hastada iatrojenik kolon perforasyonu meydana geldi. Iatrojenik kolon perforasyonu tanısı konulan hastaların yaş ortalaması 62 idi (minimum: 27, maksimum: 83) (Tablo 1).

Hastaların 7 tanesine kolonoskopi esnasinda, 1 tanesine ise kolonoskopiden 24 saat sonra iatrojenik kolon perforasyonu tanısı konuldu. Bu çalışmada iatrojenik kolon perforasyon oranı \%0.22 olarak belirlendi. Hastalarımızın 6 tanesinde sigmoid kolon proksimalinde, 2 tanesinde ise inen kolonda perforasyon tespit edildi. Tüm hastalarda meydana gelen perforasyon kolonskopun travması sonucu oluştu. Hastalarda görülen perforasyon boyutu ise 1-3 cm arasında değişmekte idi.

Kolonoskopi sırasinda perforasyon tespit edilen 7 hastadan 5 tanesine primer kolorafi, 1 tanesine primer kolografi ve ince barsakta tümör saptandığı için beraberinde ince barsak rezeksiyon anastomozu ve geriye kalan l'ine ise divertikülozise bağlı perforasyon olduğu için Hartmann prosedürü uyguland. Kolonoskopi issleminden 24 saat sonra kolon perforasyonu saptanan diğer hastaya ise Hartmann prosedürü uygulandı. Ameliyat sonrası hiçbir olgumuzda mortalite gözükmezken, 2 olgumuzda yara yeri enfeksiyonu gelişti (Tablo 1).

\section{TARTISSMA}

Nadir olarak ortaya çıkmasına rağmen kolonoskopiye bağlı olarak şekillenen en ciddi komplikasyonlardan biri iatrojenik kolon perforasyonudur. Yüksek mortalite ve morbiditeye sahip olan iatrojenik kolon perforasyonu genellikle cerrahi müdahale gerektirir. Kolonoskopide elektrokoter uygulamalarında küçük perforasyonlar, mekanik yaralanmalarda büyük perforasyonlar meydana gelebilir (3). Deneyimli merkezlerde iatrojenik kolon yaralanması ortalama \%0.016-08 oranındadır $(4,5)$. Bizim çalışmamızda da 9 yıllık tanısal ve işleme dayalı kolonoskopide perforasyon oranı \%0.22 olarak belirlendi.

Iatrojenik perforasyon en fazla sigmoid kolon ve rektosigmoid bileşkede meydana gelmektedir (6). Bizim çalışmamızda da en fazla sigmoid kolonda perforasyon mevcuttu. Kolonoskopide perforasyon riskini arttıran faktörler; yaş, inflamatuvar barsak hastalığı, divertikülozis, steroid kullanımı, malignite, invaziv işlemler ve endoskopistlerin deneyimsizliği şeklinde sıralanabilir (3). Literatürde endoskopistin deneyimsiz olması da iatrojenik kolon perforasyonuna predispozan bir faktör $(1,2)$ olarak gösterilmesine rağmen bu durumun oranını belirten bir çalışmaya literatürde rastlanmamıştır. Çalışmamızda, 7 olgumuzda da endoskopistin bu konuda yeterli deneyime sahip olmadığı için perforasyon gelişstiği düşünüldü. Çünkü bu perforasyonlar endoskopi eğitimi alındıktan sonra, bu endoskopistlerin işlemleri yaptıkları ilk günlerde ortaya çıktı. Diğer taraftan iatrojenik perforasyon için bir risk faktörü olarak görülen divertikülosis veya divertikülit durumu da hava insuflasyonu sırasında perforasyon oluşturabilir (7). Çalışmamızda olgularımızın 1 tanesinde divertikülitin perforasyonu kolaylaştırdığı veya sekonder olarak perforasyona neden olduğu tespit edildi. Bu hastada sol alt kadran ağrisı olan ve çekilen bilgisayarlı tomografide şüpheli kitlesel görünüm ve divertikülle uyumlu bulgu saptand. Hastaya kolon tümörü şüphesi nedeniyle kolonoskopi planlandı. Kolonoskopide

Tablo 1. Olguların demografik ve klinik bulguları

\begin{tabular}{|c|c|c|c|c|c|c|c|c|}
\hline $\begin{array}{c}\text { Hasta } \\
\text { No }\end{array}$ & Yaş & Cinsiyet & Tanı & İsslem & $\begin{array}{c}\text { Tespit Edilme } \\
\text { Zamanı }\end{array}$ & $\begin{array}{c}\text { Perforasyon } \\
\text { Yeri }\end{array}$ & Tedavi & Sonuç \\
\hline 1 & 83 & K & Karın ağrısı etiyolojisi & Kolonoskopi & İşem sırasında & Inen kolon & $\begin{array}{c}\text { Primer kolografi }+ \text { ince } \\
\text { bağırsak rezeksiyon + } \\
\text { anastomoz }\end{array}$ & Şifa \\
\hline 2 & 74 & $\mathrm{~K}$ & Kronik konstipasyon & Kolonoskopi & 24 saat sonra & Sigmoid kolon & Hartmann kolostomi & $\begin{array}{c}\text { Yara yeri } \\
\text { enfeksiyonu }\end{array}$ \\
\hline 3 & 59 & K & Divertikülosis & Kolonoskopi & İşlem sırasında & Sigmoid kolon & Hartmann kolostomi & $\begin{array}{c}\text { Yara yeri } \\
\text { enfeksiyonu }\end{array}$ \\
\hline 4 & 27 & E & Anemi etiyolojisi & Kolonoskopi & İşlem sırasında & Sigmoid kolon & Primer kolografi & Şifa \\
\hline 5 & 69 & K & Kronik konstipasyon & Kolonoskopi & Işlem sırasında & Sigmoid kolon & Primer kolografi & Şifa \\
\hline 6 & 79 & K & Karın ağrısı etiyolojisi & Kolonoskopi & Isslem sırasında & İnen kolon & Primer kolografi & Şifa \\
\hline 7 & 56 & E & Anemi etiyolojisi & Kolonoskopi & Işlem sırasında & Sigmoid kolon & Primer kolografi & Şifa \\
\hline 8 & 55 & K & Kronik konstipasyon & Kolonoskopi & Işlem sırasında & Sigmoid kolon & Primer kolografi & Şifa \\
\hline
\end{tabular}


sigmoid kolon proksimalinde birkaç adet inflame divertikül görüldü. Kolonoskopi sırasında divertikülite uyan bölgeden perforasyon olduğu gözlendi. Hastaya Hartmann prosedürü uygulandı. totrojenik perforasyonla ilgili diğer çalışmalarda diveritkülite bağlı perforasyonlar bildirilmesine rağmen etkili olduğu oran verilmemiștir. Ayrıca literatürde iatrojenik perforasyonun yaşla ilgili kolon duvarındaki yapısal değişikliklere bağlı olarak ortaya çıkmasında artış görülebileceğine ilişkin düşünceler vardır. Iatrojenik perforasyonu konu edinen çalışmalarda yaş ortalamaları 65 ve üzeri bulunurken (8) bizim çalışmamızda bu oran 62 olarak belirlenmiştir.

Perforasyondan şüphelenilen hastalarda akciğer grafisi, ayakta direkt karın grafisi, sol lateral dekübitis karın grafisi başlangıçta çekilmelidir. Grafilerde herhangi bir bulgu saptanmayan fakat perforasyon şüphesi olabilecek hastalarda ise tanı koymak için abdominal bilgisayarlı tomografi yapılmalıdır (3). Çalışmamızda olguların 7'sinde kolonoskopi sırasında iatrojenik kolonoskobik perforasyon tanısı konulduğundan grafi veya tomografi alınmadı ancak kolonoskopiden 24 saat sonra tespit edilen vakada ise çekilen ayakta direk karın grafisinde diyafram altında hava göründü ve perforasyon tanısı konuldu.

Olgularımızın 7 tanesinde perforasyon işlem esnasında tesbit edildi ve bu hastalarda perforasyon yerinin bir tanesinde inen kolon, altı tanesinde sigmoid kolon olduğu görüldü. $\mathrm{Bu}$ hastalara primer onarım yapıldı. Bu hastalarımızdan bir tanesinin öyküsünde yaklaşık iki yıl boyunca karında ara sıra ağrı şikayetiyle hastaneye başvurduğu öğrenildi. Genel cerrahi polikliniğine yine aynı şikayetle başvuran hastaya kolonoskopi planlandi. Hastanın yapilan kolonoskopisinde 70 . cm'de perforasyon meydana geldi. Ameliyata alınan hastada insidental olarak ince barsak tümörü tespit edildi. Kolona primer onarım yapilırken aynı seansta ince barsak rezeksiyon anastomoz yapildi.

Kolonoskopi esnasında hastaların \%5'inde ișlem sonrasında ağrı görülebilir. Fakat ağnı şikayeti devam ederse hastalara karın muayenesi yapılmalı ve ayakta direkt karın grafisi çekilmelidir $(9,10)$. Çalışmamızdaki bir olguda ise kolonosokopi sonrasında 1 gün devam eden karın ağrısı nedeniyle hasta tekrar hastaneye yatırıldı. Yapilan fizik muayenesinde karında hassasiyet, rebaund, defans mevcuttu. Ayakta direkt karın grafisinde diyafragma altında hava görüldü. Hasta ameliyat alındı ve Hartmann prosedürü uygulandı. Kolonoskopik perforasyonlarda konservatif, endoskopik ve cerrahi olmak üzere üç farklı tedavi seçeneği vardır. Literatürde peritoneal irritasyonun veya abdominal sepsisin olmadığı hastalarda konservatif tedavi ile küçük çaplı perforasyonların herhangi bir problem olmadan tamamen kapandığı belirtilmiştir $(2,3)$. Konservatif tedavi işlem esnasında fark edilen, peritoneal irritasyon bulgusu olmayan, retroperitoneal yerleşimli olan perforasyonlarda da denenebilir (11). Bizim çalışmamızda perforasyon 7 hastada işlem esnasında fark edildiği halde, hiçbir hastaya konservatif tedavi uygun görülmedi. Bunun nedeni hekimlerin tercihi ve hastaların ileri yaşta olmasına bağlanabilir. tatrojenik kolon perforasyonlarında olguların cerrahi tedavisinde endoskopik klip uygulamaları, laparoskopik onarım gibi seçenekler mevcuttur $(9,12)$. Endoskopik klip yöntemiyle ilgili kapama daha çok 1 cm'den küçük perforasyonlarda daha başarılıdır (13). Çalışmamızda hem vakalarımızın $1 \mathrm{~cm}$ 'den daha büyük perforasyona sahip olması hem de merkezimizde endoskopik klip uygulamalarının henüz yapılamaması ve bu konuda deneyimli endoskopistimiz bulunmadığından klip uygulamasına gidilmedi. Çalışmamızda tüm hekimlerimiz açık ameliyat tekniğini tercih etmişlerdir.

Sonuç olarak; iatrojenik kolon perforasyonu kolonoskopi esnasında görülebilecek komplikasyonlardandır. Bu nedenle hastaların işlem öncesi iyi bilgilendirilmesi gereklidir. Ayrıca işlem sonrası hastalar iyi takip edilmeli, karın ağrısı şikayeti olan hastaların iyi değerlendirilerek olası bir komplikasyonda tedavilerinin yapılması gereklidir.

\section{KAYNAKLAR}

1. Macrae FA, Tan K, Williams CB. Towards safer colonoscopy: a report on the complications of 5000 diagnostic or therapeutic colonoscopies. Gut 1983;24:376-83.

2. Heath B, Rogers A, Taylor A, Lavergne J. Splenic rupture: an unusual complication of colonoscopy. Am J Gastroenterol 1994;89:449-50.

3. Gündeş E, Çiyiltepe H, Aday U, et al. Emergency cases following elective colonoscopy: Iatrogenic colonic perforation. Turk J Surg 2017;33:248 52

4. Sagawa T, Kakizaki S, Iizuka H, et al. Analysis of colonoscopic perforations at a local clinic and a tertiary hospital. World J Gastroenterol 2012;18:4898-904.

5. Church J. Complications of colonoscopy. Gastroenterol Clin North Am 2013;42:639-57.

6. Tam MS, Abbas MA. Perforation following colorectal endoscopy: what happens beyond the endoscopy suite? Perm J 2013;17:17-21.

7. Bas G, Okan I, Erozgen F, et al. Management of iatrogenic colonic perforations related to colonoscopic examination. Turk J Colorectal Dis 2009;19:122-8

8. Gedebou TM, Wong RA, Rappaport WD, et al. Clinical presentation and management of iatrogenic colon perforations. Am J Surg 1996;172:454-

9. Byeon JS. Colonic Perforation: Can we manage it endoscopically? Clin Endosc 2013:46:495-9.

10. Hsieh $\mathrm{YH}$, Lin $\mathrm{HJ}$, Tseng KC. Limited water infusion decreases pain during minimally sedated colonoscopy. World J Gastroenterol $2011 ; 17: 2236-40$

11. Taku K, Sano Y, Fu KI, Saito Y. Iatrogenic perforation at therapeutic colonoscopy: should the endoscopist attempt closure using endoclips or transfer immediately to surgery? Endoscopy 2006;38:428.

12. Akin M, Ege B, Akin FE, et al. Colonic stricture following conservative treatment of a colonoscopic perforation. Endoscopy 2008;40(Suppl 2):E89.

13. Campos S, Amaro P, Portela F, et al. Iatrogenic perforation coloscopy in a portuguese population: A study including in and out-of-hosipital procedures. GE Prot J Gastronterol 2016;23:183-90 